\title{
Loss of BRCA1 leads to an increased sensitivity to Bisphenol A
}

\author{
Laundette P. Jones $^{\mathrm{a}, *}$, Aishia Sampson ${ }^{\mathrm{a}}$, Hyo Jin Kang ${ }^{\mathrm{b}}$, Hee Jeong Kim ${ }^{\mathrm{b}}$, Yong-Weon $\mathrm{Yi}^{\mathrm{b}}$, \\ Sun Young Kwon ${ }^{\mathrm{e}}$, Janice K. Babus ${ }^{\mathrm{f}}$, Antai Wang ${ }^{\mathrm{g}}$, Insoo Bae ${ }^{\mathrm{b}, \mathrm{c}, \mathrm{d}, * *}$ \\ a Department of Pharmacology and Experimental Therapeutics, University of Maryland, School of Medicine, Baltimore, MD 21201, United States \\ ${ }^{\mathrm{b}}$ Department of Oncology Lombardi Comprehensive Cancer Center, Georgetown University, Washington, DC 20057, United States \\ ${ }^{\mathrm{c}}$ Department of Radiation Medicine, Lombardi Comprehensive Cancer Center, Georgetown University, Washington, DC 20057, United States \\ ${ }^{\mathrm{d}}$ WCU (World Class University) Research Center of Nanobiomedical Science, Dankook University, Cheonan, South Korea \\ e Department of Pathology, Keimyung University, Dongsan-Dong, Deagu, South Korea \\ ${ }^{\mathrm{f}}$ Department of Biochemistry and Molecular Biology, University of Maryland, School of Medicine, Baltimore, MD 21201, United States \\ ${ }^{g}$ Department of Biostatistics, Herbert Irving Comprehensive Cancer Center, Columbia University, New York, NY, United States
}

\section{A R T I C L E I N F O}

\section{Article history:}

Received 27 April 2010

Received in revised form 9 September 2010

Accepted 10 September 2010

Available online 22 September 2010

\section{Keywords:}

Brca1

Mammary gland

Bisphenol A

Mice

\begin{abstract}
A B S T R A C T
Humans are chronically exposed to the plasticizer, Bisphenol A (BPA), that can adversely affect the normal hormonal regulation of cellular functions by mimicking the actions of estrogen. This biological response to BPA may vary according to an individual's genetic characteristics (e.g., BRCA1 mutations or deletion). In this study, both cell culture and mouse models were used to elucidate whether the loss of BRCA1 function could affect BPA-mediated cell proliferation. In studies using BPA levels comparable to human exposures, we found that loss of BRCA1 enhances BPA-induced cell proliferation in both systems. In vitro, we found that loss of BRCA1 enhances BPA-induced ER $\alpha$ signaling. In vivo, we found that BPA administration stimulates mammary gland epithelial tissue/cell proliferation leading to hyperplasia in Brca1 mutant mice compared to wild-type control mice. These results suggest that the biological responses in BRCA1-deficient cells may depend on environmental exposures, specifically BPA.
\end{abstract}

(c) 2010 Elsevier Ireland Ltd. All rights reserved.

\section{Introduction}

Bisphenol A (BPA) is a chemical building block widely used to manufacture polycarbonate plastics (e.g., plastic water bottles and storage containers) and epoxy resins used as protective coatings for the inner surfaces of metal food and beverage containers (Markey et al., 2002; vom Saal et al., 2007). Human exposure to BPA is widespread and studies have documented detectable levels of BPA ranging from 0.2 to $10 \mathrm{ng} / \mathrm{mL}(\sim 0.5-40 \mathrm{nM})$ in adult and fetal human serum (Welshons et al., 2006). Concerns regarding the potential deleterious effects of BPA have greatly increased in recent years due to reports of its adverse effects in animals at doses much lower than the predicted "safe" reference dose of $50 \mu \mathrm{g} / \mathrm{kg} / \mathrm{day}$ BPA (Welshons et al., 2006). Many of the adverse effects of BPA

\footnotetext{
Abbreviations: Brca1, breast cancer susceptibility gene 1; BPA, bisphenol A; ER $\alpha$, estrogen receptor alpha.

* Corresponding author at: University of Maryland, Baltimore, Bressler Bldg., Rm 4-002, 655 W. Baltimore Street, Baltimore, MD 21201, United States.

Tel.: +1 410706 7331; fax: +1 4107060032 .

** Corresponding author at: Georgetown University, Preclinical Science Bldg, LD08D, 3970 Reservoir Road, NW, Washington, DC 20057, United States. Tel.: +1 202687 5267; fax: +1 2026872847 .

E-mail addresses: ljone010@umaryland.edu (L.P. Jones), ib42@georgetown.edu (I. Bae).
}

have been attributed to its ability to mimic endogenous estrogen at nanomolar doses through the binding of estrogen receptor alpha $(E R \alpha)$ and disrupting normal endocrine signaling through regulation of ER target genes (Welshons et al., 2006; vom Saal et al., 2007). Studies have shown that early-life exposure in rodents to low, environmentally relevant doses of BPA results in persistent alterations in mammary gland morphogenesis and increased susceptibility to tumorigenesis (Keri et al., 2007; Soto et al., 2008). These and other studies have raised concerns that low, environmentally relevant doses may also impact breast cancer risk in humans. However, humans are genetically complex. It is unclear which genetic variations may be associated with an increased or decreased sensitivity to the biological effects of this compound, particularly in the adult where there is less evidence for adverse activity of BPA (vom Saal et al., 2007). It is known that breast cancer susceptibility gene 1 (BRCA1) is altered in certain families with an inherited susceptibility to breast cancer (Friedman et al., 1994; Narod and Foulkes, 2004). One function of BRCA1 that makes alterations in this gene most relevant to BPA exposure is the ability of BRCA1 to inhibit ER $\alpha$ signaling (Fan et al., 1999, 2001). Most recently, it was found that loss of full-length Brca1 function in the mouse mammary gland was associated with an abnormal response to $17 \beta$-estradiol stimulation of mammary epithelial cells that correlated with enhanced development of preneoplasia (Jones et al., 2008). (Note: current nomenclature designates the murine protein 
as Brca1 (lower case letters) and the human protein as BRCA1 (capital letters).)

Based on the mechanism of BPA's action, we hypothesized that mammary epithelial cells with loss of BRCA1 function may have an increased sensitivity to BPA-mediated mammary epithelial cell proliferation. The objective of this study was to determine the effect of BPA exposure on the proliferation of (1) mammary epithelial cells in which BRCA1 is no longer present and (2) brca $1^{-/}$mammary epithelial tissue. This study used the combination of a preclinical mouse model that effectively reproduces the pathophysiology of human BRCA1-related breast cancer and a human cell culture model using small interfering RNAs (siRNAs) to knock down the BRCA1 gene to elucidate whether (a) loss of BRCA1 function in mammary epithelial cells would enhance BPA-mediated cell proliferation; and (b) if so, whether the effects are via the ER $\alpha$ signaling pathway.

\section{Materials and methods}

\subsection{Cell culture conditions}

MCF7 was obtained from ATCC (American Type Culture Collection, Manassas, VA) and maintained in Dulbecco's Modified Eagles' Medium (DMEM) containing 5\% fetal bovine serum (FBS), 100 units $/ \mathrm{mL}$ of penicillin and $100 \mu \mathrm{g} / \mathrm{mL}$ of streptomycin. For BPA treatment, cells were cultured with DMEM without phenolred supplemented with 5\% charcoal-stripped (CS)-FBS. All cell culture reagents were purchased from BioWhittaker, Inc. (Walkersville, MD). The BPA and tamoxifen (Tam) were purchased from Sigma-Aldrich Corp. (St. Louis, MO) and dissolved in ethanol at stock concentration of $10 \mathrm{mM}$. The ICI182780 was obtained from Tocris Bioscience (Ellisville, MO) and made at $10 \mathrm{mM}$ stock solution in ethanol. Either tamoxifen or ICI182780 (ICI) was co-treated with BPA.

\subsection{Cell counting and siRNA transfection}

MCF7 cells were pre-treated with $100 \mathrm{nM}$ siRNA (control vs. BRCA1 purchased from Dharmacon, Inc., Lafayette, CO) for $72 \mathrm{~h}$ and were re-seeded with DMEM without phenol-red supplemented with $5 \%$ CS-FBS. They were then transfected with $100 \mathrm{nM}$ of fresh siRNA using Lipofectamine 2000 (Invitrogen, Carlsbad, CA). The control-siRNA sequence was 5'-gac gag cgg cac gug cac a-3' and the BRCA1-siRNA sequence was 5'-gaa gcc agc uca agc aau a-3'. The cells were treated with $1 \mu \mathrm{M}$ of BPA for $0,1,2,3$ days or various doses $(0,10,100$, or $1000 \mathrm{nM})$ of BPA for $72 \mathrm{~h}$. Then the cells were harvested by trypsinization, stained with trypan blue dye $(1: 1$ dilution) and counted with a hemocytometer to determine living cells.

\subsection{Real-time PCR}

Total RNA was isolated from MCF7 cells using TRIzol reagent (Invitrogen, Carlsbad, CA), and cDNA was synthesized using Oligo(dT) ${ }_{12-18}$ Primer (Invitrogen, Carlsbad, CA) and SuperScript ${ }^{\circledR}$ II Reverse Transcriptase (Invitrogen, Carlsbad, CA) as described by the manufacturer. Quantitative reverse transcription-PCR (qRTPCR) was performed by using SYBR Green dye (Applied Biosystems, Foster City, CA) on a 7900 HT Real-time PCR System apparatus (Applied Biosystems, Foster City, CA) in the Georgetown University Core facility. Coding gene expression was measured by the $\Delta \triangle \mathrm{Ct}$ method using GAPDH as the internal control. The following primer sequences were used: progesterone receptor (PR) forward and reverse primers $5^{\prime}$-aaa tca ttg cca ggt ttt cg- $3^{\prime}$ and $5^{\prime}$-tgc cac atg gta agg cat aa- $3^{\prime} ;$ pS2 forward and reverse primers $5^{\prime}$-cac cat gga gaa caa ggt ga- $3^{\prime}$ and $5^{\prime}$-agc cct tat ttg cac act gg-3'; GAPDH forward and reverse primers $5^{\prime}$-gta tga caa cga att tgg cta cag-3' and 5'-agc aca ggg tac ttt att gat ggt-3', respectively.

\subsection{Western blotting assays}

Total cell lysates were obtained with the lysis buffer $(20 \mathrm{mM}$ Tris- $\mathrm{HCl}$ (pH 8.0), 0.5 M NaCl, 0.25\% Triton X-100, 1 mM EDTA, $1 \mathrm{mM}$ EGTA, $1 \mathrm{mM}$ benzamidine, $1 \mathrm{mM}$ DTT, $2 \mu \mathrm{M}$ PMSF), centrifuged at $13,000 \mathrm{rpm}$ for $10 \mathrm{~min}$ at $4{ }^{\circ} \mathrm{C}$ and supernatants were collected. The proteins were separated on SDS-PAGE and transferred to PVDF membranes (Millipore, Billerica, MA). The membranes were blocked with $1 \mathrm{X}$ blocking buffer (Sigma, St. Louis, MO), incubated with primary antibodies, and washed with $1 \mathrm{X}$ PBS containing 0.01\% Tween-20. The anti-BRCA1 (C-20, Santa Cruz Biotechnology, Santa Cruz, CA), anti-progesterone receptor (PR) (C-20, Santa Cruz Biotechnology, Santa Cruz, CA), anti-pS2 (FL-84, Santa Cruz Biotechnology, Santa Cruz, CA), anti-PCNA (FL-261, Santa Cruz Biotechnology, Santa Cruz, CA) and anti- $\beta$-actin (Sigma, St. Louis, MO) antibodies were used. After incubation with horseradish peroxidase conjugated secondary antibody (Sigma, St. Louis, MO), antigen-antibody complexes were detected by enhanced chemiluminescence (ECL) (Santa Cruz Biotechnology, Santa Cruz, CA) using X-ray films (American X-ray \& Medical Supply, Jackson, CA).

\subsection{Mice, genotyping, and dosing with BPA}

Post-pubertal Brca1 conditional knockout mice (3 months of age) with two floxed Brca1 alleles $\left(\mathrm{Brca}^{\mathrm{f} / \mathrm{f}}\right)$ carrying the mouse mammary tumor virus (MMTV)-Cre recombinase gene (Brca1 1 ff; MMTV-Cre) were maintained on a C57Bl/6 genetic background (Xu et al., 1999). Non-transgenic C57Bl/6 mice were used as controls. Mice were maintained in temperature-controlled and light-controlled conditions in the University of Maryland, Baltimore animal facility. All mice were maintained in accordance with institutional guidelines approved by the University of Maryland, Baltimore Animal Care and Use Committee. Water was supplied from non-polycarbonate plastic water packs only. A rodent diet containing a fixed formula designed to minimize phytoestrogen sources (Harlan Teklad Global 2019; Madison, WI) was supplied ad libitum. The cages and bedding were not evaluated for estrogenicity because the housing conditions were the same for both groups of mice. Therefore, we assumed that animals in both groups of mice were exposed to similar trace levels of endocrine-disrupting chemicals. The presence or absence of the floxed Brca1 alleles, of wild-type Brca1 alleles, and of the MMTV-Cre was identified using polymerase chain reaction (PCR) on tail DNA as described previously (Wagner et al., 1997; Xu et al., 1999). Mice were weighed at 3 months of age and implanted with Alzet osmotic pumps (Alza Corp, Palo Alto, CA) designed to deliver either 50\% dimethyl sulfoxide (DMSO) (vehicle control, $n=13 /$ group) or $250 \mathrm{ng} \mathrm{BPA} / \mathrm{kg} /$ body wt/day dissolved in DMSO (Sigma, St. Louis, MO) ( $n=13$ /group) for 4 weeks at a flow rate of $0.22 \mu \mathrm{L} / \mathrm{h}$. The pumps were implanted in the midback/interscapular region (neck region). Based on previously reported data, we estimate that this level of BPA exposure should fall within the range of human exposures reported to date (Calafat et al., 2008). Fourth mammary glands were surgically removed at necropsy and processed for a whole mount analysis or formalin fixed for histology and immunohistochemistry (IHC).

\subsection{Mammary gland whole mount analysis, histological studies, and immunohistochemistry}

One \#4 mammary gland from each animal was dissected and spread on a glass slide at the time of necropsy for whole mount analyses as previously described (Jones et al., 2008). The other \#4 mammary gland from each mouse was fixed in $10 \%$ buffered 
A

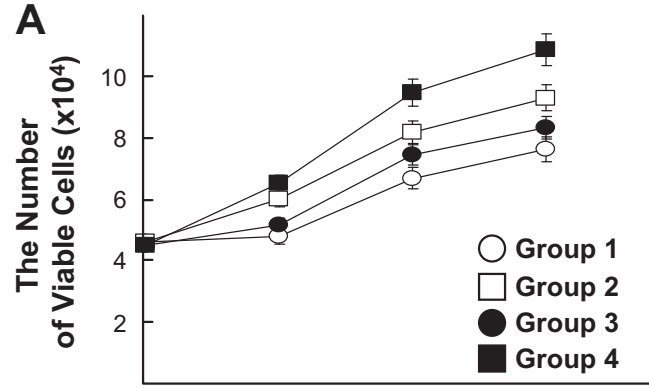

$\begin{array}{llll}\text { Day } 0 & \text { Day } 1 & \text { Day } 2 & \text { Day } 3\end{array}$

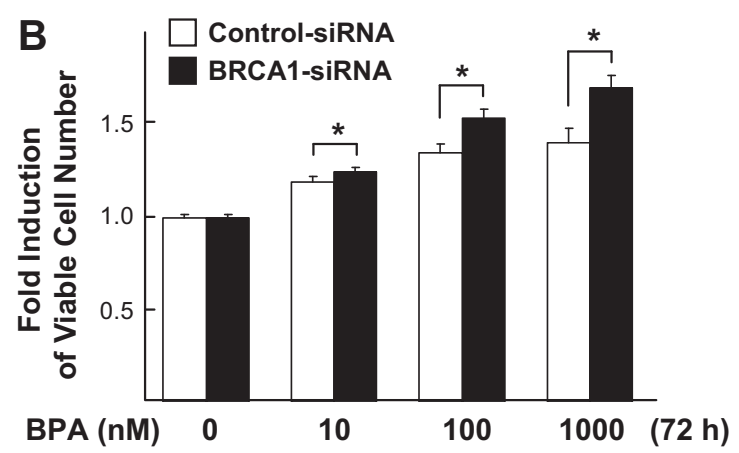

Fig. 1. BRCA1 modulates BPA-induced cell proliferation in MCF7 cells. (A) Cells pretreated with $100 \mathrm{nM}$ siRNA (control vs. BRCA1) for $72 \mathrm{~h}$ were re-seeded and further transfected with fresh siRNA for $24 \mathrm{~h}$. Then, the cells were treated with $1 \mu \mathrm{M}$ of BPA for $0,1,2$ and 3 days and the numbers of viable cells were counted $(N=10)$. Values are mean \pm S.E.s of the viable cell numbers. One-way analysis of variance (ANOVA) and the Turkey test were used to analyze these data. Note the followings: Group 1=Control-siRNA, Group 2=Control-siRNA + BPA, Group 3= BRCA1-siRNA and Group $4=$ BRCA1-siRNA + BPA. At day 1 , there were significant differences in groups 1 vs. 3,1 vs. 4,2 vs. 3 and 2 vs. $4(F=19.32, P<0.0001)$. At day 2 , significant differences were found between all pairs except for group 1 vs. $2(F=35.18$, $P<0.0001)$. At day 3 , significant differences were found between all pairs except for group 2 vs. $3(F=20.83, P<0.0001)$. (B) Cells were transfected with siRNA in the same way as described in $(A)$ and treated with various doses of BPA $(0,10,100$, $1000 \mathrm{nM}$ ) for $72 \mathrm{~h}$. We applied two sample $t$-test, for we compared values of the two samples (control vs. BRCA1-siRNA) at each BPA concentration $\left({ }^{*} P<0.05\right)$. The numbers of cells were counted and normalized to the control cells without BPA treatment.

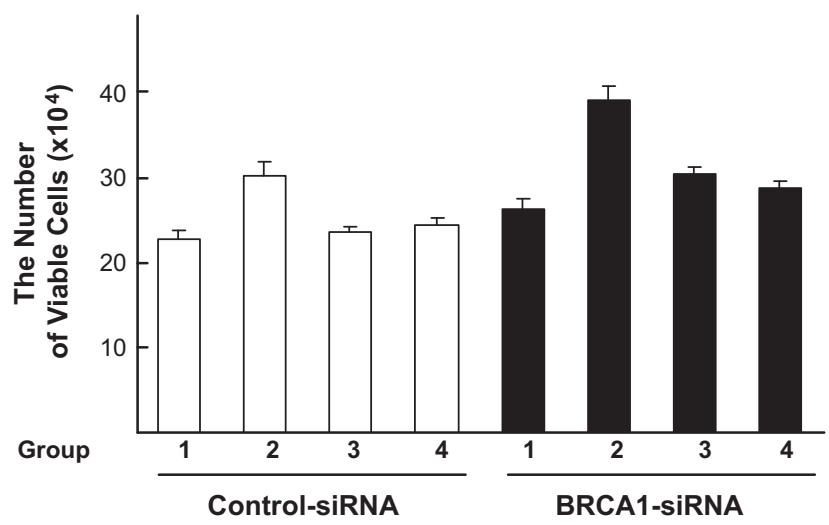

Fig. 2. $E R \alpha$ antagonists inhibit BPA-induced cell proliferation in the presence or absence of endogenous BRCA1. MCF7 cells pre-treated with siRNA as in Fig. 1 were incubated with $1 \mu \mathrm{M}$ BPA alone, $1 \mu \mathrm{M}$ BPA $+1 \mu \mathrm{M}$ Tamoxifen (Tam) or $10 \mu \mathrm{M}$ of ICI182780 (ICI) for $72 \mathrm{~h}$, and the viable cells were counted. Either Tam or ICI was co-treated with BPA. We conducted ANOVA plus Tukey test. Note the followings: Group $1=$ no treat, Group $2=$ BPA, Group $3=B P A+T a m$, and Group $4=B P A+I C I$. For the control-siRNA treated group the $\mathrm{F}$ value was 1.04 and $P$ value was 0.3905 . For BRCA1-siRNA treated group the $F$ value was 6.17 and $P$ values was 0.0023 . There were significant differences in groups 1 vs. 2,2 vs. 3 , and 2 vs. 4 , but no significant differences were found between 1 vs. 3 and 3 vs. 4 in BRCA1-siRNA treated group.
A
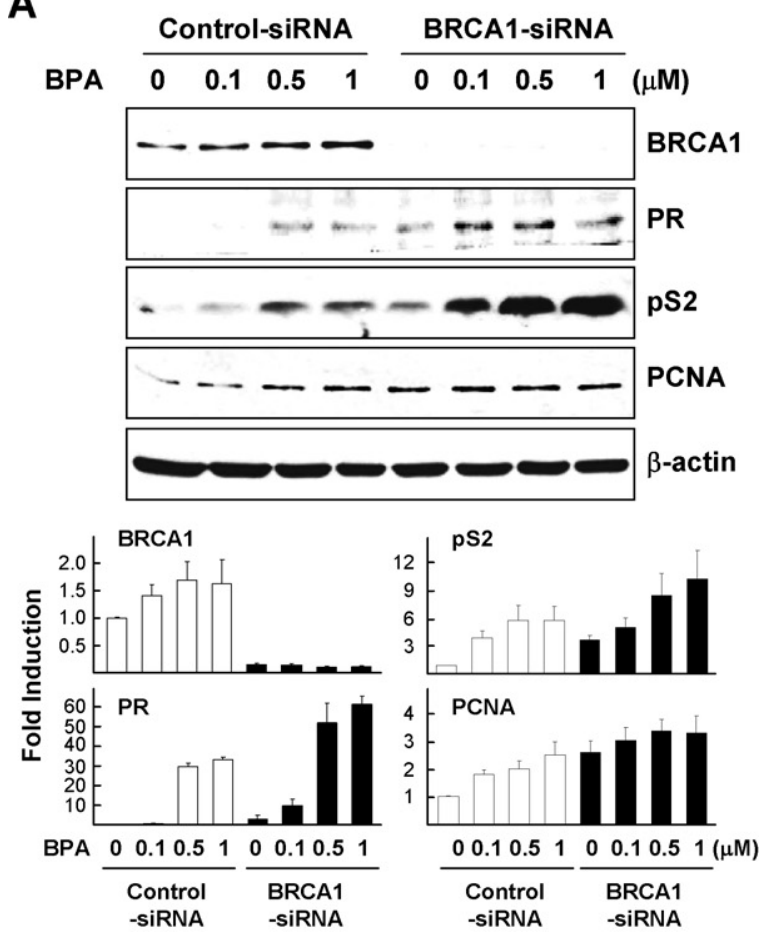

B

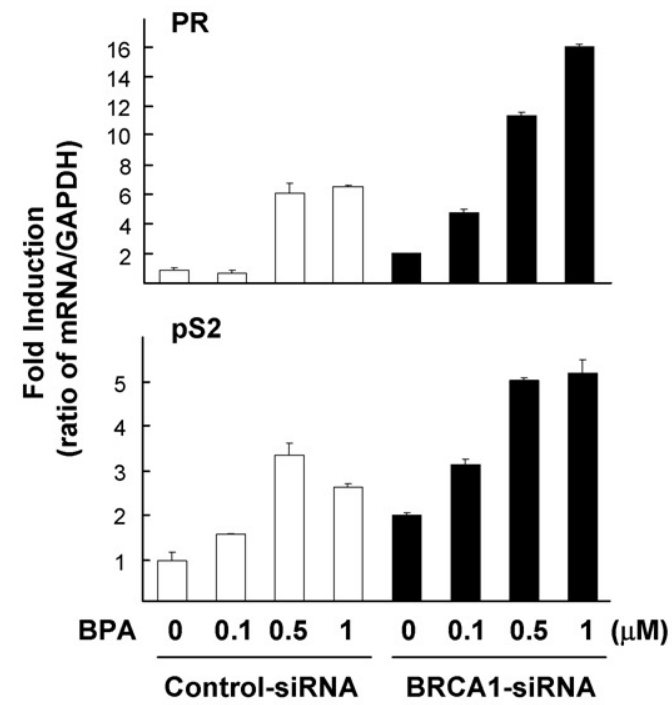

Fig. 3. BRCA1 modulates BPA-induced ER $\alpha$ target gene expression. (A) MCF7 cells pre-treated with $100 \mathrm{nM}$ siRNA (control vs. BRCA1) as in Fig. 1 were treated with various doses of BPA for $24 \mathrm{~h}$. Upper panel: the expression levels of proteins were analyzed by western blot using anti-BRCA1, anti-progesterone receptor (PR), antipS2, anti-PCNA, and anti- $\beta$-actin antibodies in total cell lysates. Lower panel: densitometric analyses of western blot. For each gene, we conducted two-way ANOVA instead of one-way ANOVA, one factor is BRCA1-siRNA vs. control-siRNA and the other factor is different concentration of BPA treatment groups. BRCA1: $F=19.83$, $P<0.0001$ Group $F=76.4 P<0.0001$, BPA treatment $F=0.98 P=0.4152$. PR: $F=66.63$, $P<0.0001$ Group $F=42.98 P<0.0001$, BPA treatment $F=74.52 P<0.0001$. pS2: $F=10.78, P<0.0001$ Group $F=15.24 P<0.0004$, BPA treatment $F=9.29 P=0.0001$. PCNA: $F=8.77, P<0.0001$ Group $F=24.55 P=0.0004$, BPA treatment $F=3.51 P=0.023$. (B) The levels of mRNA expression were analyzed by gene-specific primers for PR or pS2. Total RNA harvested from the cells treated as in (A) was used for quantitative real-time PCR as described in 2.3. PR: $F=17.85, P<0.0001$ Group $F=26.43 P=0.0003$, BPA treatment $F=19.98 P=0.0003$. Tukey test demonstrated significant differences between groups 1 vs. 3, 2 vs. 3, 1 vs. 4 , and 2 vs. 4 (see Fig. 1 for the description of groups 1-4). However, the differences in groups 1 vs. 2 and 3 vs. 4 were not significant. pS2: $F=22.55, P<0.0001$ Group $F=24.72 P=0.0004$, BPA treatment $F=21.83$ $P<0.0001$. Tukey test results were significant between groups 1 vs. 3,2 vs. 3,1 vs. 4 , and 2 vs. 4 . But, there were no statistical differences were found between groups 1 vs. 2 and 3 vs. 4 . 

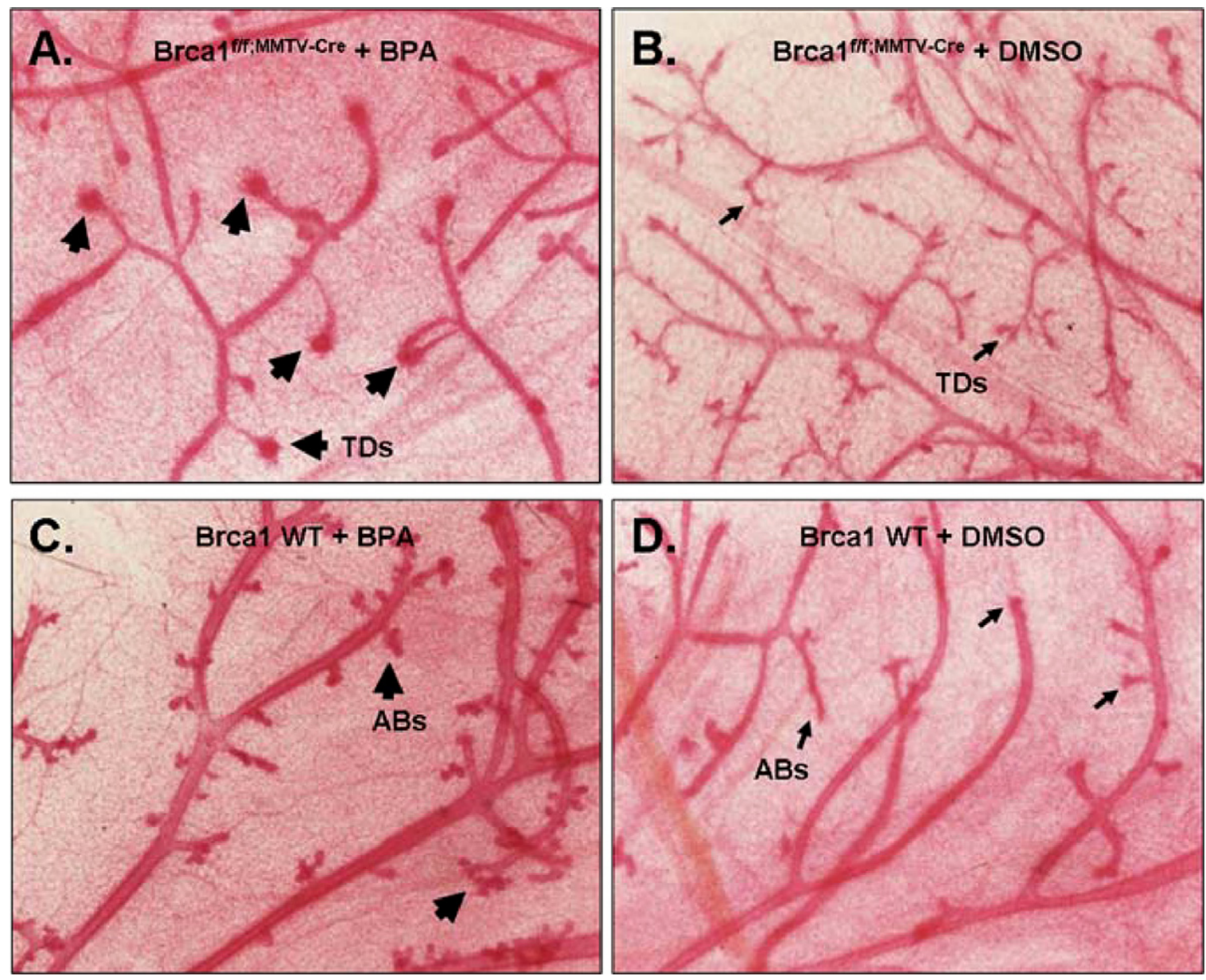

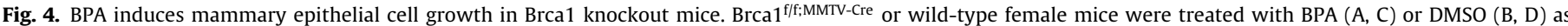

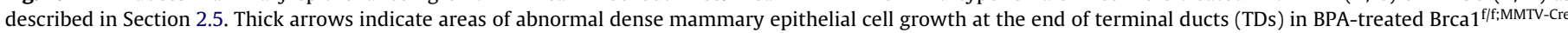

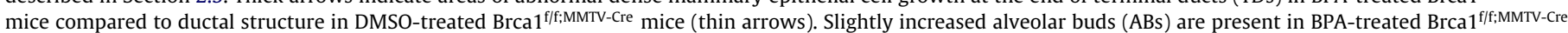
mice compared to normal appearing Abs in DMSO-treated wild-type mice (thin arrows). Magnification, 40×.

formalin (Fisher Scientific, Pittsburgh, PA) overnight at $4^{\circ} \mathrm{C}$ and embedded in paraffin using standard techniques. Five-micron sections were cut for hematoxylin and eosin (H\&E) staining and IHC detection was performed as described previously (Jones et al., 2008) using PCNA (1:400, FL-261, Santa Cruz Biotechnology, Santa Cruz, CA). Seven nonadjacent sections from each mammary gland of each mouse were examined for the presence or absence of normal ductal structures and hyperplasia. The percentage of cells demonstrating positively stained nuclei (proliferative index) was determined by counting a minimum of 1000 cells per section. One section from each mouse was selected randomly and consecutive fields examined under $40 \times$ magnification until a total of 1000 cells were counted. Digital photographs were taken using a Nikon 50i Upright Microscope System with a high resolution, 5 Megapixel Color Digital Camera system (Nikon Instruments Inc., Melville, NY).

\subsection{Statistical analyses}

Means and standard errors of the mean (S.E.) were calculated for proliferation, numbers of viable cells, mRNA expression levels, and PCNA expression. Each outcome measure has different groupings, which are individually described with each associated figure legend. Two-tailed Student's $t$-tests were implemented when only 2 groups of interest were compared. For comparisons with multiple groups, one-way or two-way ANOVA were implemented. After the overall analysis is done for each data set, Tukey tests control- ling the type one error have been performed to make the pairwise comparison between the treatment groups.

\section{Results}

\subsection{Knockdown of BRCA1 significantly enhanced BPA-mediated cell proliferation}

Since we are interested in effects of BRCA1 levels on BPAstimulated cell proliferation, MCF7 cells pre-treated with $100 \mathrm{nM}$ siRNA (control vs. BRCA1) for $72 \mathrm{~h}$ were reseeded and further transfected with fresh siRNA for $24 \mathrm{~h}$ to ensure almost complete knockdown of BRCA1. Then, the cells were treated with $1 \mu \mathrm{M}$ of BPA for $0,1,2$ and 3 days and the viable cells were counted by trypan blue exclusion assays. As a consequence, we found that BRCA1 knockdown itself could significantly enhance cell proliferation on day 1 to day 3 . Loss of BRCA1 also significantly enhances BPAinduced cell proliferation from day 2 to day 3 (Fig. 1A). Next, we investigated the effects of various doses of BPA on breast cancer cell proliferation. As in Fig. 1A, MCF7 cells pre-treated with $100 \mathrm{nM}$ siRNA (control vs. BRCA1) for $72 \mathrm{~h}$ were reseeded and further transfected with fresh siRNA for $24 \mathrm{~h}$ and were incubated with various amounts of BPA $(0,10,100$ or $1000 \mathrm{nM})$ for $72 \mathrm{~h}$. We found that BPA increased cell proliferation in a dose-dependent manner in both control and BRCA1 siRNA-treated cells. BRCA1 knockdown conferred a greater BPA-mediated cell proliferation response compared to control (Fig. 1B). 

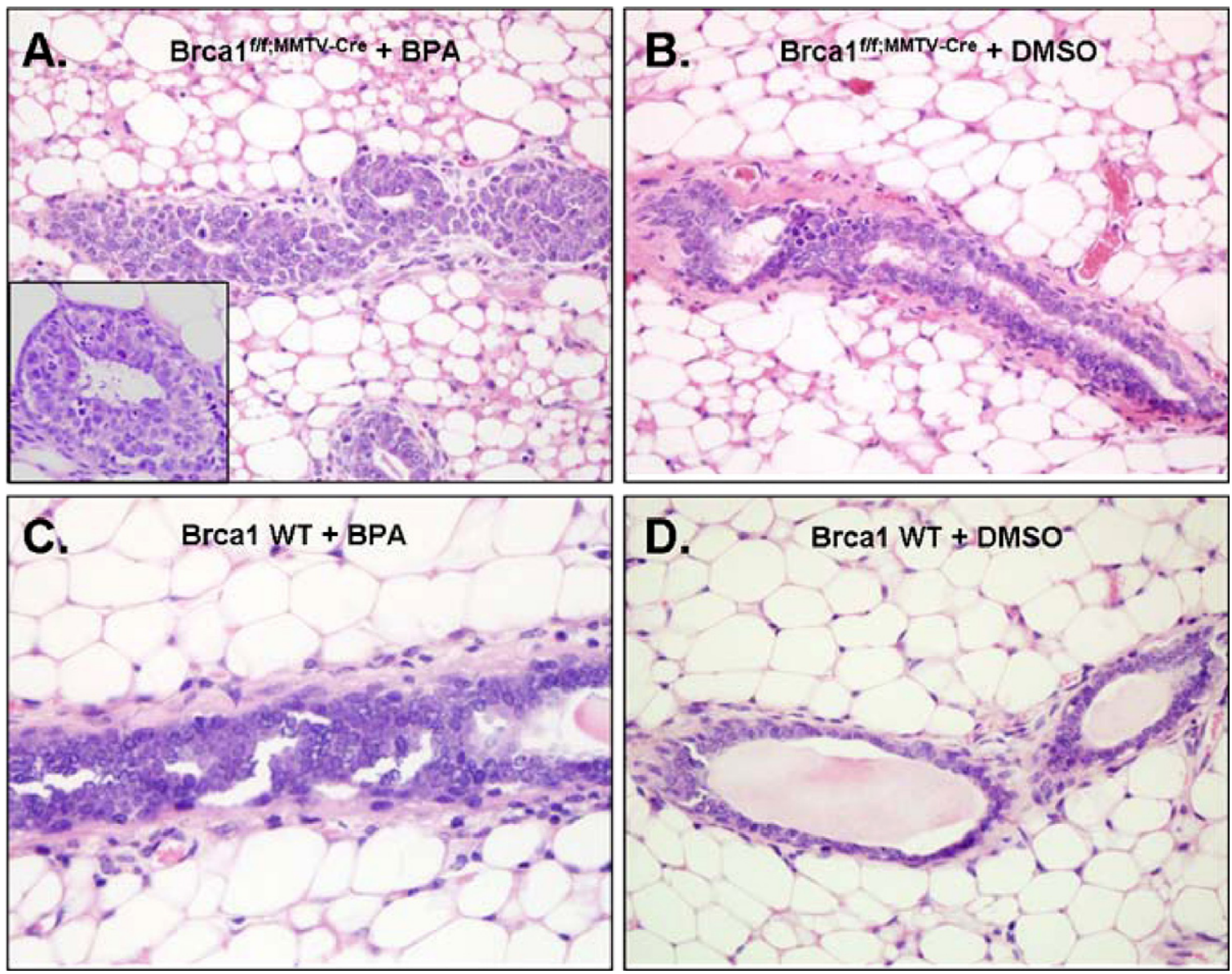

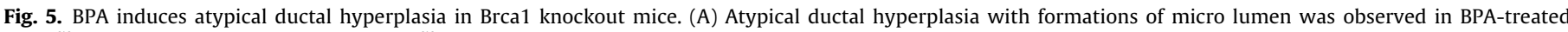

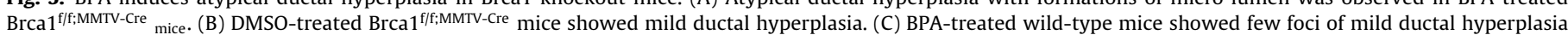
compared to (D) DMSO-treated wild-type mice where no structural changes of mammary gland were observed. Magnification, $40 \times$; inset magnification, $100 \times$.

\subsection{Tamoxifen or ICI182780 inhibits BPA-induced cell proliferation in the presence and absence of BRCA1}

Since BPA stimulates ER $\alpha$ signaling pathway (Schafer et al., 1999; Hess-Wilson et al., 2006), and BRCA1 is a known repressor for ER $\alpha$ signaling pathway (Fan et al., 1999; Zheng et al., 2001), we asked whether the increase of cell proliferation in BRCA1-siRNA treated cells was due to the loss of BRCA1 function in repressing $\mathrm{ER} \alpha$ signaling. When cells were co-treated with $\mathrm{ER} \alpha$ antagonists, Tamoxifen (Tam) or ICI182780 (ICI), BPA-induced cell proliferation was significantly repressed in BRCA1-siRNA transfected cells (Fig. 2). These results suggest that the increase of BPA-stimulated cell proliferation in BRCA1 knockdown cells is dependent upon ER $\alpha$ signaling.

\subsection{BRCA1 knockdown enhances BPA-induced ERa target gene expression}

Next, we tested whether BRCA1 knockdown modulates BPAinduced ER $\alpha$ target gene and protein expression. Cells similarly treated with siRNA as in Fig. 1 were incubated with various doses of $\operatorname{BPA}(0,0.1,0.5,1 \mu \mathrm{M})$ for $24 \mathrm{~h}$. In this experiment, we confirmed that BPA treatment increased estrogen target gene products, pS2 and PR (Schafer et al., 1999; Hess-Wilson et al., 2006). In addition, we found that the level of PCNA protein, a cell proliferation marker, was also increased by BPA treatment in both BRCA1 knockdown cells and control cells (Fig. 3A). In order to determine whether endogenous BRCA1 affects ER $\alpha$-mediated transcriptional regulation activity following BPA, total RNA was isolated from cells treated with siRNA $\pm B P A$ as in Fig. $3 A$ and used for a real-time PCR analysis. As expected, we found that BPA-mediated ER $\alpha$ target gene expression (pS2 and PR) was significantly increased in BRCA1 knockdown cells (Fig. 3B). We also found that a lower dose $(0.05 \mu \mathrm{M})$ can stimulate $\mathrm{PS} 2$ and PR gene expression more in BRCA1 knockdown cells (data not shown).

\subsection{BPA treatment alters mammary gland morphology in Brca1 ${ }^{f / f}$;MMTV_Cre female mice}

To test the effect of BRCA1 mammary gland response to BPA in vivo, adult virgin female Brca1/f;:MMTV-Cre mice or wild-type nontransgenic mice at 3 months of age were implanted with Alzet osmotic pumps (slow release of $250 \mathrm{ng} \mathrm{BP} \mathrm{A} / \mathrm{kg} /$ body wt/day or DMSO) for 4 weeks. After 4 weeks of osmotic pump implantation, the mice were euthanized, necropsied, and the mammary glands were removed. At first, mammary glands were examined by whole mount for morphological changes of ductal structures. The whole mount sections of BPA-treated Brca $1^{\mathrm{f} / \mathrm{f} ; \mathrm{MMTV} \text {-Cre }}$ mice revealed more dense mammary epithelial cell growth at the end of terminal ducts (TDs) (Fig. 4A, arrows) compared to DMSO-treated Brca 1/f;:MMTV-Cre mice (Fig. 4B). Also the whole mount sections of BPA-treated wildtype mice (Fig. 4C) showed slightly increased alveolar buds (ABs) with no definite evidence of increased density in TDs. The control specimens from DMSO-treated wild-type mice (Fig. 4D) had no specific abnormalities compared to other specimens. 
In addition to these morphologic features, we searched the H\&E stained histology for ductal epithelial hyperplasia with or without the cytologic atypical changes, such as enlarged nuclei, prominent nucleoli, mitotic figures, or apoptotic bodies. The microscopic findings revealed that BPA-stimulated mammary epithelial cells demonstrated abnormal hyperplasia in $69.2 \%$ (9 out of 13 ) of

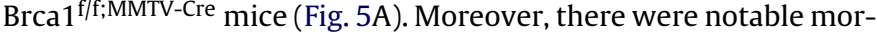
phological alterations in BPA-treated Brca $1^{\mathrm{f} / \mathrm{f} ; \mathrm{MMTV}-\mathrm{Cre}}$ mice such as intraductal lumen formation (Fig. $5 \mathrm{~A}$, inset). In contrast, these hyperplastic epithelial changes were only observed in $28 \%$ ( 4 out of

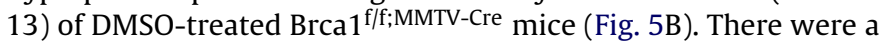
few foci of mild ductal hyperplasia in BPA-treated wild-type mice (Fig. 5C). No structural changes of mammary gland were observed in DMSO-treated wild-type mice (Fig. 5D).

\subsection{BPA increases mammary epithelial cell proliferation in BrCa $^{1 f / f ; M M T V-C r e}$ female mice}

The immunohistochemistry of PCNA was utilized to examine the proliferative response of BPA in mammary epithelial cells in mice (Fig. 6). Mammary epithelial cell proliferation was distinctively increased in BPA-treated Brca1/f;:MMTV-Cre mice (BPA vs. DMSO-treated, $65.6 \pm 9.5 \%$ vs. $32.3 \pm 4.5 \%$, ANOVA F-test contrast, $P=0.02$; Fig. $6 \mathrm{~A}$ and $\mathrm{B}$ ). Also, there were significant differences, in the proliferation index in wild-type mice (BPA vs. DMSO-treated, $37.7 \pm 4.2 \%$ vs. $14.3 \pm 1.4 \%$, ANOVA $F$-test contrast $P<0.001$; Fig. 6C and D). Fig. $6 \mathrm{E}$ presents the PCNA positive cells and proliferation index for each genotype and treatment combination.
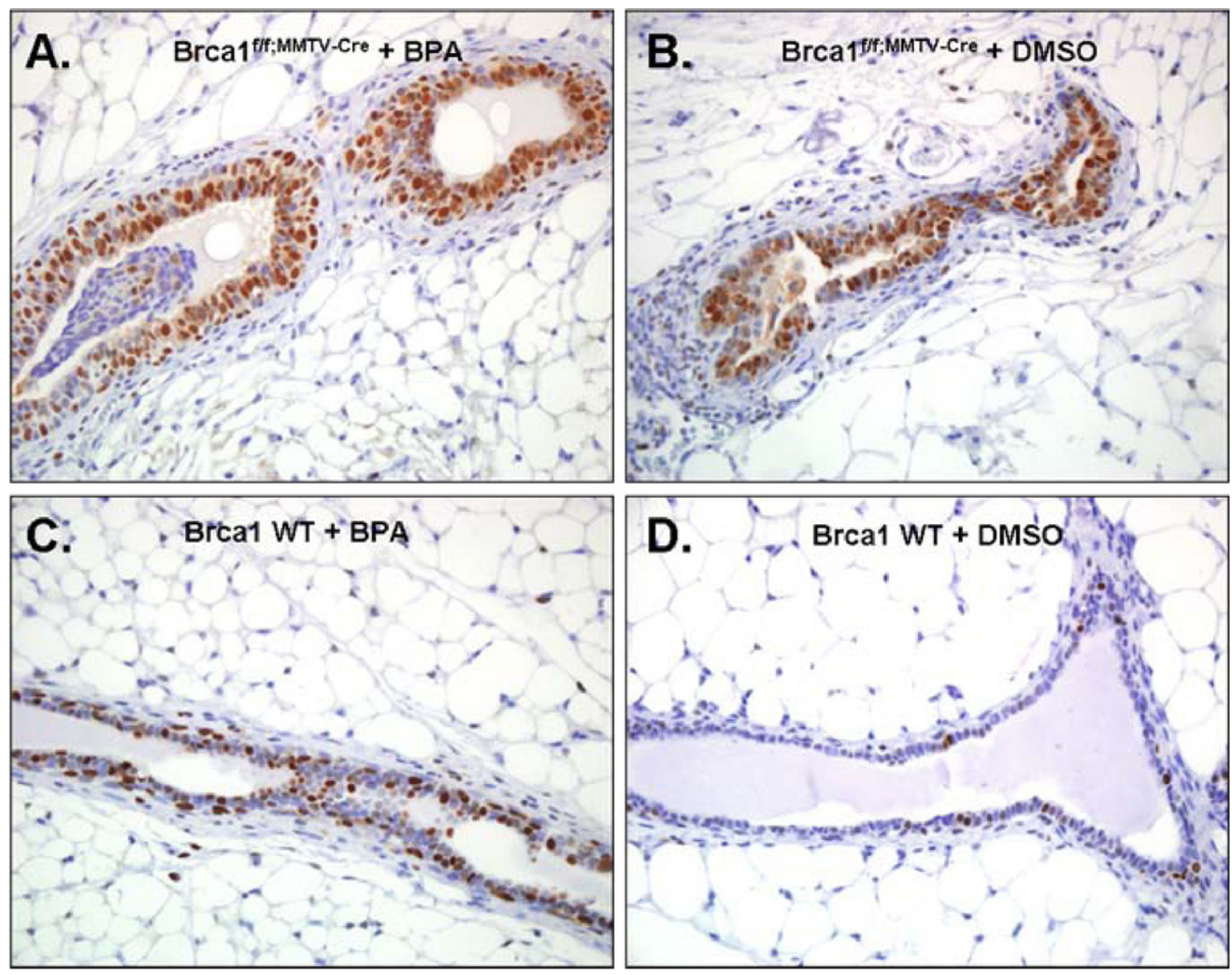

E. Effect of treatments on cell proliferation in Mammary ductal epithelial cells.

\begin{tabular}{lccccc}
\hline \multicolumn{1}{c}{ Treatments } & No. of Mice & No. of fields & No. of total & \multicolumn{2}{c}{ No. of PCNA Proliferation Index } \\
lmoll counts & -positive & (Mean \pm S.E.) \\
\hline Brca1 WT + DMSO & 7 & 10 & 7000 & 1003 & $14.3 \pm 1.4 \%$ \\
Brca1 WT + BPA & 7 & 10 & 7000 & 3191 & $37.7 \pm 4.2 \%$ \\
Brca1 1/f;MMTV-Cre + DMSO & 7 & 10 & 7000 & 2743 & $32.3 \pm 4.5 \%$ \\
Brca1 f/f;MMTV-Cre + BPA & 7 & 10 & 7000 & 4610 & $65.6 \pm 9.5 \%$ \\
\hline
\end{tabular}

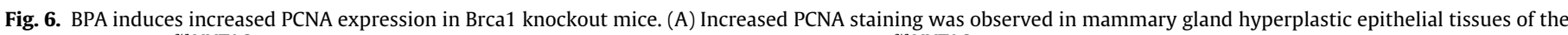

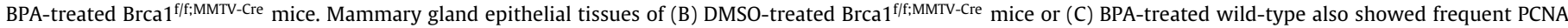

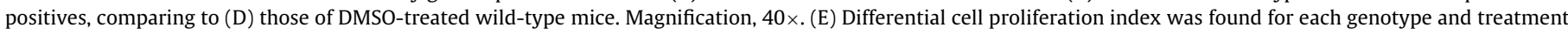
of combination (DMSO or BPA). 


\section{Discussion}

In this study, we have investigated the effects of BPA on mammary epithelial cells in vitro and in vivo with and without functional BRCA1. Our data indicate that exposure to BPA in vitro enhances proliferation in cells with loss of BRCA1 (by siRNA), in a dose-and time-dependent manner. Additionally, BPA exposure in vivo at a low environmentally relevant dose $(250 \mathrm{ng} / \mathrm{kg})$ increased mammary epithelial cell proliferation and hyperplasia in post-pubertal Brca1 knockout mouse mammary glands.

The dose range of BPA required to stimulate cell proliferation in our MCF7 cells is similar to that reported by others using different MCF7 cell stocks in E-Screen assay studies (Villalobos et al., 1995). On the contrary, in the same dose range, BPA has a much more profound effect on stimulation of cell proliferation in MCF7 cells with loss of BRCA1 function. Additionally, co-exposure with the estrogen receptor antagonists Tamoxifen (Tam) or ICI182780 (ICI) inhibited BPA-induced cell proliferation in the presence and absence of BRCA1 indicating the involvement of ER $\alpha$ in the induced cell growth. Since BRCA1 is known to positively regulate cell proliferation arrest genes (e.g., Gadd45 and p21) (Harkin et al., 1999; Somasundaram et al., 1997), BPA-induced cell proliferation in BRCA1 knockdown cells may not be exclusively dependent upon ER $\alpha$ signaling. Interestingly, when low concentration of Tam was added, a reduced inhibition of BPA-induced cell proliferation was observed in BRCA1 knockdown cells (data not shown), which implies that non-ER $\alpha$ pathway may be also involved in BPAinduced MCF7 cell proliferation.

The BRCA1 protein has been linked to a broad number of generic cellular processes including regulation of DNA repair, chromatin remodeling, and cell cycle checkpoint control (Narod and Foulkes, 2004; Rosen et al., 2005). One function of BRCA1, however, that makes alterations in this gene most relevant to BPA exposure is the ability of BRCA1 to inhibit ER $\alpha$ signaling to proliferation. Fan et al. (1999) have postulated that BRCA1 has a repressive effect on genomic ER $\alpha$-mediated gene transcription. Hence, we have used parameters related to estrogen signaling as markers to determine whether a decrease in BRCA1 expression levels alters BPA-induced gene expression. Consistent with previous reports, BPA induced PR (Krishnan et al., 1993; Olea et al., 1996) and pS2 gene transcription (Olsen et al., 2003; Soto et al., 1995) in MCF7 cells (Fig. 3B). Higher dose of the BPA $(1 \mu \mathrm{M})$, however, did not further increase gene expression (i.e., PR) or was slightly less responsive compared to $0.5 \mu \mathrm{M}$ BPA (i.e., pS2) in MCF7 cells with functional BRCA1. Previously, the "nonmonotonic" nature of BPA on growth of human prostate adenocarcinoma cells has been reported (Wetherill et al., 2002). To establish whether our observation is a true nonmonotonic effect, further experiments will be needed with a wider range of doses (Vandenberg et al., 2009). Interestingly, this nonmonotoniclike phenomenon was not detected at least in PR gene expression in MCF7 cells with BRCA1 knockdown.

In the present study, we have also demonstrated that postpubertal exposure to an environmentally relevant dose of BPA led to a significantly increased growth response in mammary epithelial cells of virgin mice with a deficiency in Brca1 compared to wild-type mice. It is likely that the increase in proliferation contributes to the abnormal mammary gland morphology observed in BPA-treated Brca $1^{\mathrm{f} / \mathrm{f} ; \mathrm{MMTV} \text {-Cre }}$ mice. The BPA-induced changes in mammary gland morphology and proliferation in Brca1-deficient mice were similar to the physiological effects of exogenous $17 \beta$ estradiol, which stimulates an increase in mammary epithelial cell proliferation in this same model (Jones et al., 2008). Our findings suggest that Brca1 may function to limit the physiological growth response to BPA.

This study demonstrates that the xenoestrogen BPA acts as a mitogen in mammary epithelial cells with loss of BRCA1 function.
These effects, observed both in vitro and in vivo, occur at very similar levels to those measured in circulating blood of humans (Calafat et al., 2005; Tsutsumi, 2005; Yamada et al., 2002). Additional studies in animals will be conducted using more animals per group and several BPA dosages (verification with BPA plasma/serum measurements) to determine the consistency of these preliminary findings and to determine if the effects observed in the present study are dose-responsive. However, our current data suggest that loss of BRCA1 function may enhance BPA effects via estrogen-related pathways. This study highlights the importance of conducting research to understand how differences in genetic factors can affect sensitivity to environmental exposures.

\section{Conflict of interest}

The authors have no conflicts of interest.

\section{Acknowledgments}

Dr. Jones has been supported by NIH/NICHD K12HD 043489 and the University of Maryland Marlene and Stewart Greenebaum Cancer Center Institutional Research Grant 9715307 and Maryland Cigarette Restitution Funds. Dr. Bae has been supported by Susan G. Komen for the Cure (FAS0703858) and by R31-10069 (WCU program) through the National Research Foundation of Korea funded by the Ministry of Education, Science and Technology. We thank Drs. Priscilla Furth and Chuxia Deng for facilitating the production of the described Brca $1^{\mathrm{f} / \mathrm{f} ; \mathrm{MMTV}-\mathrm{Cre}}$ mice. We appreciate BioMedText, Inc./Dr. Rashmi Nemade for helpful discussions and editing.

\section{References}

Calafat, A.M., Kuklenyik, Z., Reidy, J.A., Caudill, S.P., Ekong, J., Needham, L.L., 2005. Urinary concentrations of bisphenol A and 4-nonylphenol in a human reference population. Environ. Health Perspect. 113, 391-395.

Calafat, A.M., Ye, X., Wong, L.Y., Reidy, J.A., Needham, L.L., 2008. Exposure of the U.S. population to bisphenol A and 4-tertiary-octylphenol: 2003-2004. Environ. Health Perspect. 116, 39-44.

Fan, S., Wang, J., Yuan, R., Ma, Y., Meng, Q., Erdos, M.R., Pestell, R.G., Yuan, F., Auborn, K.J., Goldberg, I.D., Rosen, E.M., 1999. BRCA1 inhibition of estrogen receptor signaling in transfected cells. Science 284, 1354-1356.

Fan, S., Ma, Y.X., Wang, C., Yuan, R.Q., Meng, Q., Wang, J.A., Erdos, M., Goldberg, I.D., Webb, P., Kushner, P.J., Pestell, R.G., Rosen, E.M., 2001. Role of direct interaction in BRCA1 inhibition of estrogen receptor activity. Oncogene 20, 77-87.

Friedman, L.S., Ostermeyer, E.A., Lynch, E.D., Szabo, C.I., Anderson, L.A., Dowd, P., Lee, M.K., Rowell, S.E., Boyd, J., King, M.C., 1994. The search for BRCA1. Cancer Res. 54, 6374-6382.

Harkin, D.P., Bean, J.M., Miklos, D., Song, Y.H., Truong, V.B., Englert, C., Christians, F.C., Ellisen, L.W., Maheswaran, S., Oliner, J.D., Harber, D.A., 1999. Induction of GADD45 and JNK/SAPK-dependent apoptosis following inducible expression of BRCA1. Cell 97, 575-586.

Hess-Wilson, J.K., Boldison, J., Weaver, K.E., Knudsen, K.E., 2006. Xenoestrogen action in breast cancer: impact on ER-dependent transcription and mitogenesis. Breast Cancer Res. Treat. 96, 279-292.

Jones, L.P., Tilli, M.T., Assefnia, S., Torre, K., Halama, E.D., Parrish, A., Rosen, E.M., Furth, P.A., 2008. Activation of estrogen signaling pathways collaborates with loss of Brca1 to promote development of ER $\alpha$-negative and ER $\alpha$-positive mammary preneoplasia and cancer. Oncogene 27, 794-802.

Keri, R.A., Ho, S.M., Hunt, P.A., Knudsen, K.E., Soto, A.M., Prins, G.S., 2007. An evaluation of evidence for the carcinogenic activity of bisphenol A. Reprod. Toxicol. 24, 240-252.

Krishnan, A.V., Stathis, P., Permuth, S.F., Tokes, L., Feldman, D., 1993. Bisphenol-A: an estrogenic substance is released from polycarbonate flasks during autoclaving. Endocrinology 132, 2279-2286.

Markey, C.M., Rubin, B.S., Soto, A.M., Sonnenschein, C., 2002. Endocrine disruptors: from wingspread to environmental developmental biology. J. Steroid Biochem. Mol. Biol. 83, 235-244.

Narod, S.A., Foulkes, W.D., 2004. BRCA1 and BRCA2: 1994 and beyond. Nat. Rev. Cancer 4, 665-676.

Olea, N., Pulgar, R., Peres, P., Olea-Serrano, F., Rivas, A., Novillo-Fertrell, A. Pedraza, V., Soto, A.M., Sonnenschein, C., 1996. Estrogenicity of resin-based composites and sealants used in dentistry. Environ. Health Perspect. 104, 298-305.

Olsen, C.M., Meussen-Elholm, E.T., Samuelsen, M., Holme, J.A., Hongslo, J.K., 2003. Effects of the environmental oestrogens bisphenol A, tetrachlorobisphenol A, tetrabromobisphenol A, 4-hydroxybiphenyl and 4,4'-dihydroxybiphenyl on 
oestrogen receptor binding, cell proliferation and regulation of oestrogen sensitive proteins in the human breast cancer cell line MCF-7. Pharmacol. Toxicol. 92, 180-188.

Rosen, E.M., Fan, S., Isaacs, C., 2005. BRCA1 in hormonal carcinogenesis: basic and clinical research. Endocr. Relat. Cancer 12, 533-548.

Schafer, T.E., Lapp, C.A., Hanes, C.M., Lewis, J.B., Wataha, J.C., Schuster, G.S., 1999. Estrogenicity of bisphenol A and bisphenol A dimethacrylate in vitro. J. Biomed. Mater. Res. 45, 192-197.

Somasundaram, K., Zhang, H., Zheng, Y.X., Houvras, Y., Peng, Y., Zhang, H., Wu, G.S., Licht, J.D., Weber, B.L., El-Deiry, W.S., 1997. Arrest of the cell cycle by the tumorsuppressor BRCA1 requires the CDK-inhibitor p21 WAF1/CiP1 . Nature 389, 187-190.

Soto, A.M., Sonnenschein, C., Chung, K.L., Fernandez, M.F., Olea, N., Serrano, F.O., 1995. The E-SCREEN assay as a tool to identify estrogens: an update on estrogenic environmental pollutants. Environ. Health Perspect. 103, 113-122.

Soto, A.M., Maffini, M.V., Sonnenschein, C., 2008. Neoplasia as development gone awry: the role of endocrine disruptors. Int. J. Androl. 31, 288-293.

Tsutsumi, O., 2005. Assessment of human contamination of estrogenic endocrinedisrupting chemicals and their risk for human reproduction. J. Steroid Biochem. Mol. Biol. 93, 325-330.

Vandenberg, L.N., Maffini, M.V., Sonnenschein, C., Rubin, B.S., Soto, A.M., 2009. Bisphenol-A and the great divide: a review of controversies in the field of endocrine disruption. Endocr. Rev. 30, 75-95.

vom Saal, F.S., Akingbemi, B.T., Belcher, S.M., Birnbaum, L.S., Crain, D.A., Eriksen, M., Farabollini, F., Guillette Jr., L.J., Hauser, R., Heindel, J.J., Ho, S.M., Hunt, P.A., Iguchi, T., Jobling, S., Kanno, J., Keri, R.A., Knudsen, K.E., Laufer, H., LeBlanc, G.A., Marcus, M., McLachlan, J.A., Myers, J.P., Nadal, A., Newbold, R.R., Olea, N., Prins, G.S., Richter, C.A., Rubin, B.S., Sonnenschein, C., Soto, A.M., Talsness, C.E., Vanden- bergh, J.G., Vandenberg, L.N., Walser-Kuntz, D.R., Watson, C.S., Welshons, W.V., Wetherill, Y., Zoeller, R.T., 2007. Chapel Hill bisphenol A expert panel consensus statement: integration of mechanisms, effects in animals and potential to impact human health at current levels of exposure. Reprod. Toxicol. 24, 131-138.

Villalobos, M., Olea, N., Brotons, J.A., Olea-Serrano, M.F., Ruiz de Almodovar, J.M., Pedraza, V., 1995. The E-screen assay: a comparison of different MCF7 cell stocks. Environ. Health Perspect. 103, 844-850.

Wagner, K.U., Wall, R.J., St-Onge, L., Gruss, P., Wynshaw-Boris, A., Garrett, L., Li, M. Furth, P.A., Hennighausen, L., 1997. Cre-mediated gene deletion in the mammary gland. Nucleic Acids Res. 25, 4323-4330.

Welshons, W.V., Nagel, S.C., vom Saal, F.S., 2006. Large effects from small exposures. III. Endocrine mechanisms mediating effects of bisphenol A at levels of human exposure. Endocrinology 147, S56-S69.

Wetherill, Y.B., Petre, C.E., Monk, K.R., Puga, A., Knudsen, K.E., 2002. The xenoestrogen bisphenol A induces inappropriate androgen receptor activation and mitogenesis in prostatic adenocarcinoma cells. Mol. Cancer Ther. 1, 515524.

Xu, X., Wagner, K.U., Larson, D., Weaver, Z., Li, C., Ried, T., Hennighausen, L Wynshaw-Boris, A., Deng, C.X., 1999. Conditional mutation of Brca 1 in mammary epithelial cells results in blunted ductal morphogenesis and tumour formation. Nat. Genet. 22, 37-43.

Yamada, H., Furuta, I., Kato, E.H., Kataoka, S., Usuki, Y., Kobashi, G., Sata, F., Kishi, R. Fujimoto, S., 2002. Maternal serum and amniotic fluid bisphenol A concentrations in the early second trimester. Reprod. Toxicol. 16, 735-739.

Zheng, L., Annab, LA., Afshari, C.A, Lee, W.H., Boyer, T.G., 2001. BRCA1 mediates ligand-independent transcriptional repression of the estrogen receptor. Proc Natl. Acad. Sci. U.S.A. 98, 9587-9592. 